\section{A family of T-cell alloantigens linked to Igh-1}

\section{Gwendoline M. Spurll \& Frances L. Owen}

Departments of Pathology, Cancer Research and Hematology, Tufts University Medical School, Boston, Massachusetts 02111, USA

Tsu ${ }^{d}$ (ref. 1) is an alloantigen on mouse suppressor $T$ cells, coded for by a gene downstream from the immunoglobulin locus on chromosome $12^{2}$. We now report a second T-cell alloantigen, Tind $^{d}$, which is closely linked to Tsu ${ }^{d}$. Both antigens may be products of a family of genes coding for conserved, non-antigen binding site regions of $T$-cell receptors. Tind $^{d}$ is defined by a monoclonal BALB/c (Igh-1 $\left.{ }^{a}\right)$ anti-C.AL-20 (Igh-1 ${ }^{\text {d) }}$ ) antibody and is expressed preferentially on Lyt $1^{+} 2^{-3}$ peripheral lymphoid cells, whereas $\mathrm{Tsu}^{\mathrm{d}}$ is expressed on Lyt $1^{-} 2^{+} 3^{+}$ suppressor cells. The interpretation that these determinants represent antigen binding molecules is in part based on the antibody-mediated induction of cell function. In vivo treatment of C.AL-20 animals with anti-Tsu ${ }^{d}$ antiserum at day 4 suppresses the primary immune response to sheep red blood cells (SRBCs) $^{3-5}$. Pretreatment with limiting dilutions of anti-Tind ${ }^{d}$ antibody induces cyclic waves of either suppression or enhancement of the plaque-forming cell response. The genes coding for these determinants have now been mapped in inbred congeneic mice having recombination events in or near the immunoglobulin locus. Monoclonal anti-Tind ${ }^{\mathrm{d}}$ antibodies pre- $^{-}$ cipitate a group of polypeptides of molecular weights (MWs) $62,000,45,000$ and 17,000 from ${ }^{35} \mathrm{~S}$-methionine-labelled spleen cells activated with concanavalin $A(C o n A)$ whereas the polypeptides associated with the Tsu ${ }^{\mathrm{d}}$ specificity have MWs $69,000,45,000$ and 25,000 . The differences in molecular weights and contrast in the Lyt phenotype of cells expressing these antigens suggest they are separate molecules and may imply discrete isotypes of $\mathbf{T}$-cell receptor.

We previously described the production of an alloantiserum which may recognize the constant region of a $T$-cell receptor for antigen $^{1-5}$. Antibody directed against the Igh-1-linked alloantigen blocks the binding of $\mathrm{Ts}_{2}$ cells from hyperimmune suppressed mice ${ }^{6}$ to the Ars $\operatorname{IdX}^{7}$ and acts as a polyclonal activator of suppressor $\mathrm{T}$ cells for $\mathrm{T}$-dependent antigens ${ }^{4}$. If antibody binds to a constant region of the receptor on cells for all antigens, then cross-linking of the cell surface might trigger the cells $^{8}$ in the observed antigen-independent manner ${ }^{4}$. The genetic restrictions imposed on the antibody-induced ${ }^{5}$ suppressor cells mirror those reported previously for regulatory cells for major cross-reactive idiotypes ${ }^{9}$. Antisera having these properties were used to precipitate a ${ }^{35} \mathrm{~S}$-methionine-labelled complex of antigens from extracts of spleen tissue cultures from allotype congeneic pairs of mice (Fig. 1). The major species precipitated is a 69,000-MW polypeptide, although antigens of MWs 45,000 and 25,000 co-precipitated in variable c.p.m. ratios in different cell preparations. The structural relationship between these antigens is unclear, although the appearance of the 69,000-MW molecule critically depends on the use of proteolytic inhibitors throughout the preparation preceding electrophoresis. Figure 1 shows that these antigens are C.AL-20 specific and are not present on the BALB/c cell, as predicted by the strain pattern ${ }^{1}$ of induction of suppressor $\mathrm{T}$ cells.

We have now produced a monoclonal antibody using a modification of this immunization protocol. The $\gamma 1 \kappa$-secreting line, 9IIIA2, produces an antibody (anti-Tind ${ }^{d}$ ) which recognized an antigen(s) on C.AL-20 cells that is similar to but antigenically distinct from $T s u^{d}$. The antigen (Tind ${ }^{\mathrm{d}}$ ) comprises polypeptides of MWs $62,000,45,000$ and 17,000 and is detected in a strain-specific pattern (Fig. 2). BALB/c and C.B.AL-1

㽞
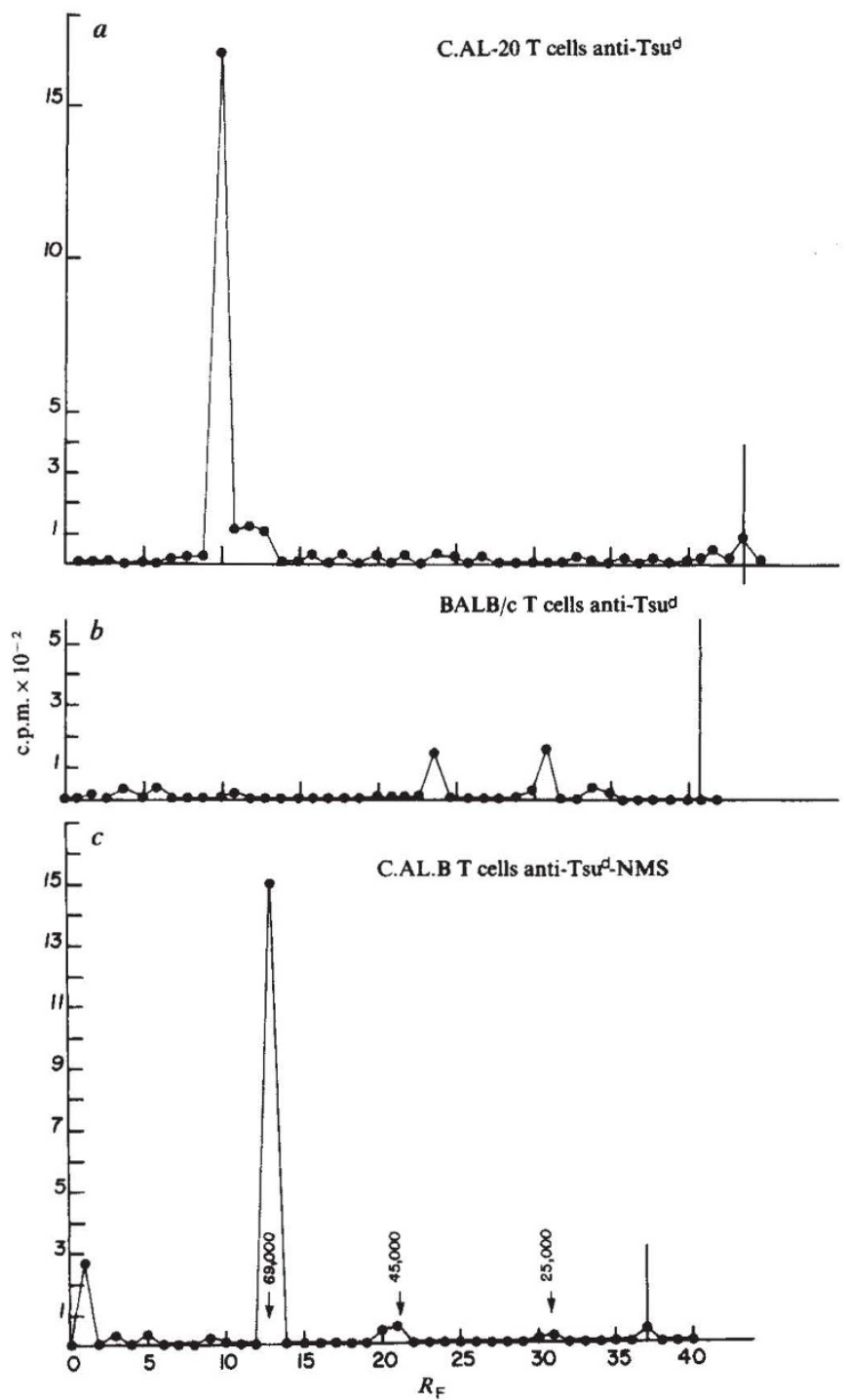

Fig. 1 SDS-polyacrylamide gel electrophoresis of ${ }^{35} \mathrm{~S}$-methionine-labelled antigens synthesized by splenic cells stimulated with Con $A$ for $48 \mathrm{~h}$ from: $a$, C.AL-20 (Igh-1 $\left.{ }^{d}\right) ; b$, BALB $/ c\left(I g h-1^{a}\right) ; c, C . A L . B\left(I g h-1^{d}, \mathrm{H}-2^{b}\right)^{20}$ animals. Cells $\left(2 \times 10^{7} \mathrm{ml}^{-1}\right)$ were metabolically labelled by incubating washed cells in methionine-free RPMI for $4 \mathrm{~h}$ with $100 \mu \mathrm{Ci}$ of ${ }^{35} \mathrm{~S}$-methionine and washing three times with phosphate-buffered saline (PBS) before extracting. Cell extracts were obtained by lysing washed cells three times in $1 \mathrm{ml}$ of buffer containing $0.01 \mathrm{M} \mathrm{NaPO}, 0.1 \mathrm{M} \mathrm{NaCl}, 1 \%$ Triton X-100, $0.5 \%$ deoxycholate, $0.1 \%$ SDS and $0.0025 \mathrm{M}$ phenylmethylsulphonyl fluoride. Supernatants from a $35,000 \mathrm{~g}$ centrifugation $(90 \mathrm{~min})$ of cell extracts were incubated with $5 \mu \mathrm{l}$ of anti-Tsu ${ }^{\mathrm{d}}$ antiserum chosen from early bleeds of selected sera known to contain the biological activity for the Tsu ${ }^{d}$ gene product ${ }^{1-4}$ or with $5 \mu \mathrm{l}$ of normal mouse serum. Extracts were incubated with glutaraldehyde-fixed Staphylococcus aureus organisms (Immunosorb) precoated with sheep anti-mouse IgG1-antiserum. Labelled antigen was eluted from washed adsorbent in buffer containing $5 \%$ SDS, $0.25 \mathrm{M}$ Tris pH 6.8, and $2.5 \% 2$-mercaptoethanol and electrophoresed on $12 \%$ tube acrylamide gels ${ }^{21}$ cross-linked with DATD ${ }^{22}$ in Tris-glycine buffer for $2.5 \mathrm{~h}$ at a constant current of $3 \mathrm{~mA}$ per gel at $25^{\circ} \mathrm{C}$. Sliced gels were incubated with $5 \%$ Protosol in Econofluor scintillation fluid from $12 \mathrm{~h}$ before counting at $25^{\circ} \mathrm{C}$.

animals, which were previously shown to lack the Tsu ${ }^{\mathrm{d}}$ gene, also lack this alloantigen. The C.B.AL-1 mouse has documented recombination events on chromosome 12 which limit the position of the gene(s) coding for the new specificity to a region of chromosome 12 between $V_{H}$ Dex and a recombination event between $\mathrm{Tsu}^{\mathrm{d}}$ and prealbumin ${ }^{10}$ (Table $1 b$ ). This region encompasses the proposed IgT region ${ }^{1}$. The close proximity of $\mathrm{Tsu}^{\mathrm{d}}$ and Tind ${ }^{\mathrm{d}}$ suggests that a family of T-cell-specific polypeptides may be encoded here. Further investigation of 
hyperimmune anti-Tsu ${ }^{d}$ alloantisera identifies the second Tind ${ }^{d}$ specificity as a 'contaminant' band in precipitation studies and also shows a larger band in C.AL-20 but not BALB/c cells, of unknown function. Monoclonal antibody or alloantiserum coupled to Sepharose 4B was used to preabsorb cell extract before precipitation with anti-Tind ${ }^{d}$ or anti-Tsu ${ }^{d}$ antibody. Coupling of anti-Tind ${ }^{\mathrm{d}}$ antibody to Sepharose 4B and preclearing cell extracts before addition of anti-Tsu ${ }^{d}$ serum removes the 62,000 - and 17,000-MW peaks from the ${ }^{35} \mathrm{~S}$-methionine-precipitated material but does not preclear the 69,000- and 25,000MW polypeptides. Therefore, the 62,000-, 45,000- and 17,000MW polypeptides precipitated with anti-Tsu ${ }^{d}$ are those molecules recognized by anti-Tind ${ }^{\mathrm{d}}$. The 69,000-, 45,000- and 25,000-MW molecules do not appear to cross-react serologically with the $62,000-, 45,000$ - and $17,000-\mathrm{MW}$ molecules.

The $\mathrm{T}$-cell determinants recognized by anti-Tsu ${ }^{\mathrm{d}}$ or antiTind ${ }^{d}$ antibody are not expressed on serum immunoglobulins. Antisera directed against immunoglobulin isotypes (summarized in Fig. 2) do not preclear or co-precipitate these antigens. In addition, ammonium sulphate-precipitated ascites protein from clone 9IIIA2 (anti-Tind ${ }^{\mathrm{d}}$ ) was labelled with ${ }^{125} \mathrm{I}$ and incubated with plates coated with either BALB/c or C.AL-20 normal mouse immunoglobulin. Anti-Tind ${ }^{\mathrm{d}}$ antibody fails to bind serum immunoglobulins.

The biological properties of the cell(s) displaying Tind ${ }^{d}$ have not been defined. Visual fluorescence staining experiments suggest that $3-5 \%$ of mature peripheral $T$ cells eluted from nylon wool are positive. Negative selection with monoclonal anti-Lyt-1.2 or anti-Lyt-2.2 antibodies and complement followed by visual surface fluorescence suggests preferential expression of this determinant on an Lyt-1.2 high-density cell in contrast to the preferential expression of Tsu ${ }^{d}$ on Lyt-2.2 cells $^{2,3}$. Staining of thymocytes, bone marrow or splenic B cells by monoclonal anti-Tind ${ }^{d}$ antibody cannot be detected visually.

In vivo pretreatment of mice with anti-Tind ${ }^{d}$ antisera before injection of SRBCs either enhances (induction of help) or reduces (induction of suppression) the response. The cyclic induction of an altered response depends on when the antiserum is administered. The results are reminiscent of the hypothetical waves of suppressor and helper cells postulated to interact in regulating the idiotypic response of mice ${ }^{11,12}$ and may represent either sequential steps or biological alternatives in a regulatory network ${ }^{13}$. An Lyt-1 $1^{+}$inducer $\mathrm{T}$ cell which initiates Lyt- $2^{+}$, $3^{+}$-mediated suppression was hypothesized ${ }^{14}$, although no relationship between Tind ${ }^{d}$ and that cell has been tested experimentally.

Fig. 2 Monoclonal antibody against Tind ${ }^{d}$ from clone 9IIIA2 precipitates a complex of antigens with a molecular weight distinct from that of Tsud. This monoclonal cell line was obtained by fusion of spleen cells from mice immunized with a protocol similar to that reported to raise antibody to Tsu (refs 1-4). BALB/c AnN mice were immunized twice intravenously (i.v.) with C.AL-20 cells activated with Con $A$ and fused 3 days after the last injection. Spleen cells from immune donors were fused with BALB/c myeloma P.3U1 (ref. 23), a non-secreting variant of a BALB/c myeloma, with $30 \%$ polyethylene glycol. Fused cells were grown in HAT (hypoxanthine, aminopterin and thymidine), Dulbecco's high glucose medium with $10 \%$ horse serum in 96 -well microtitre plates ${ }^{24}$. The fusion frequency was $30 \%$ and 9 IIIA 2 cells subcloned on thymocyte feeder layers had a $50 \%$ cloning efficiency. Subclones develop in 10-12 days as visible clones. The hybridoma line has been subcloned sequentially three times and grown in vitro for 6 months as a secreting line. Subcloned lines are maintained in $10 \%$ horse serum in Dulbecco's H-21 medium with essential amino acids, nonessential amino acids, sodium pyruvate, glutamine, penicillin/streptomycin. $c, d$ And $e$ show later bleeds of the same alloantiserum shown in Fig. 1 (additional strain specific molecules are detectable). The antigens precipitated by clone 9IIIA2 (frame $a, b, f$ ) correspond to the $62,000-, 45,000$ and $17,000-\mathrm{MW}$ species detectable in the late bleeds of the alloantiserum. The following control antisera were ineffective in blocking or preabsorbing the molecules precipitated by anti-Tsu ${ }^{d}$ antibody: affinity-purified classspecific anti-isotype reagents ${ }^{25}$ (rabbit anti-mouse IgG2a, anti-HOPC-1, $25 \mu \mathrm{g}$ binding capacity (b.c.); sheep anti-mouse IgG3, anti-J606, $250 \mu \mathrm{g}$ b.c.; goat anti-mouse IgM, anti-ABPC-22, $720 \mu \mathrm{g}$ b.c.; rabbit anti-IgM, anti-ABPC-22, $10 \mu \mathrm{g}$ b.c.; rabbit anti-mouse IgD, anti-MOPC $1017,5 \mu 1$ serum or $50 \mu \mathrm{g} \mathrm{Fab}$ fragments of affinity-purified antibody); monoclonal anti-Thy-1.2, $10^{8}$ lytic units; monoclonal anti-Lyt-1.2, $10^{8}$ lytic units; goat anti-Rauscher GP70 serum, $5 \mu 1$.
Cyclic waves of enhancement or suppression are induced when $5 \mathrm{ng}$ of antibody is administered at different times over 10 days. The time of appearance of the crest of these waves varies between experiments but the magnitude of the crest is constant (Fig. 3). In fact, one observes either the pattern in Fig. $3 a$ or that in Fig. $3 b$; they are mirror images. In contrast, when the time (day 4 ) is held constant and the antibody concentration varied, $5 \mu \mathrm{l}$ of tissue culture supernatant ( $\sim 5 \mathrm{ng}$ of immunoglobulin) showed a statistically significant strain-specific enhancement for the C.AL-20 animal (Table 1). The normalized grand geometric
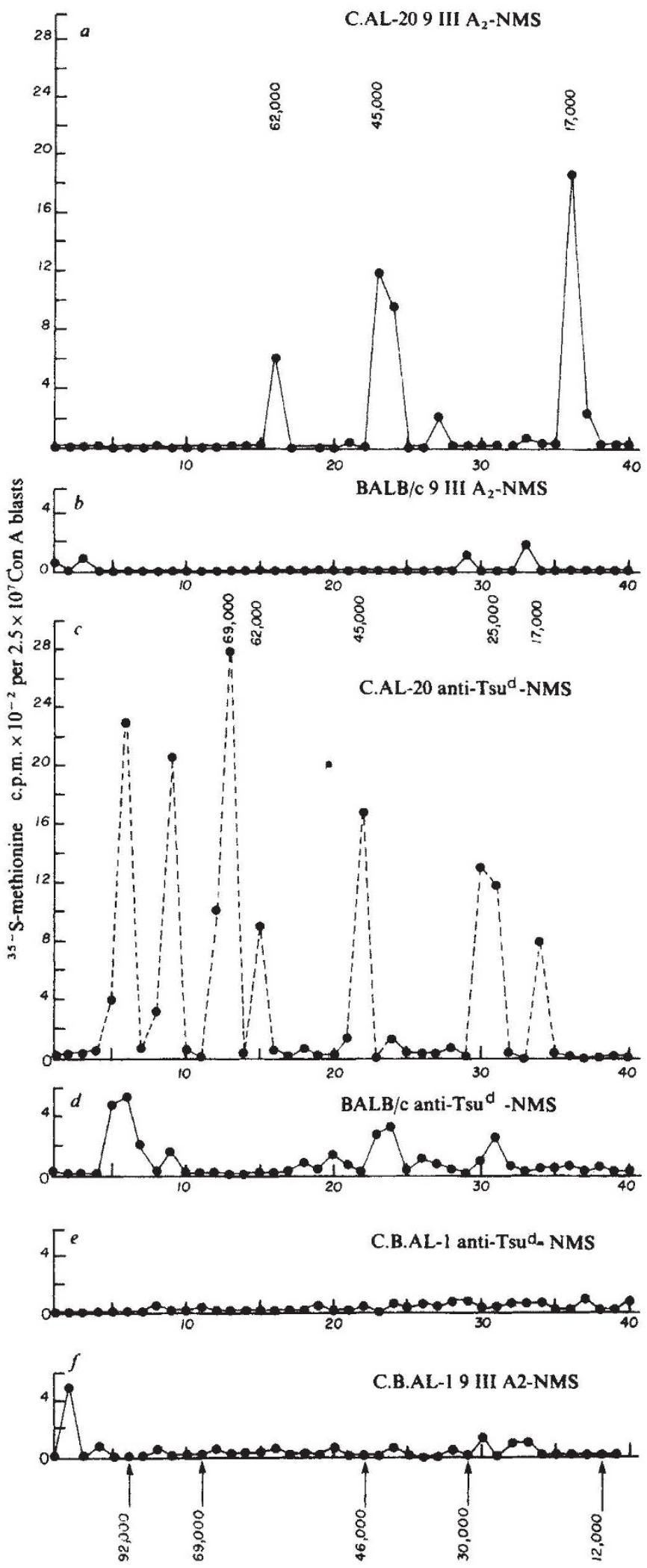
mean $\stackrel{\times}{\div}$ s.e. of 15 mice in five separate experiments was 52,987 plaque-forming cells (PFC) $\stackrel{\times}{\rightarrow} 1.23$ for control values and $108,710 \times 1.47$ for those treated with $5 \mathrm{ng}$ of antibody $(\boldsymbol{P}=$ 0.001 ). The kinetics of enhancement change rapidly (Fig. 3); the need to assay during a critical few hours in the immune response may explain why the changes range from two- to fourfold in different experiments. Table $1 b$ shows the recombination event in the C.B.AL-1 animal which limits the gene coding for this biological activity to the region of chromosome 12 mapped for $\mathrm{Tsu}^{\mathrm{d}}$ (ref. 1). As only low doses of antibody enhance the

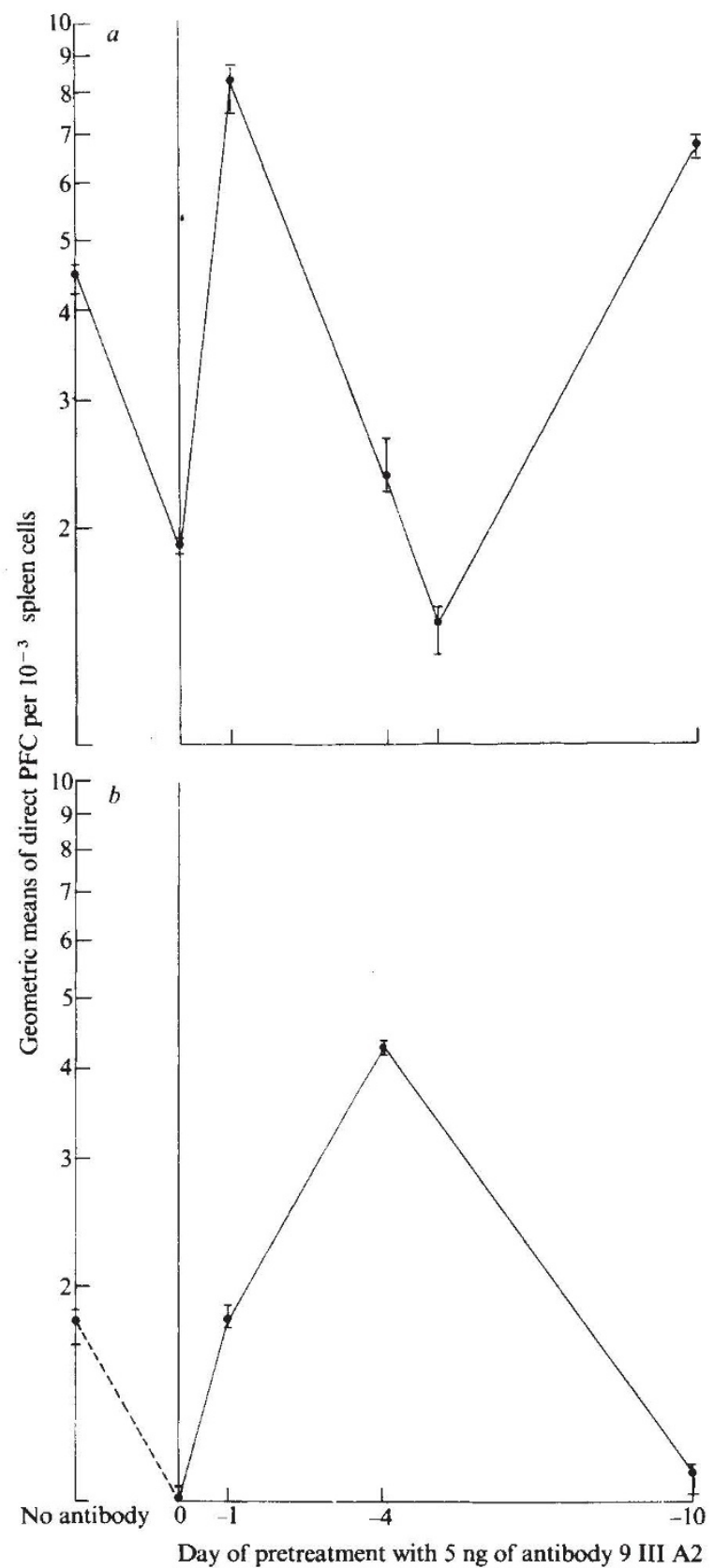

Fig. 3 Monoclonal anti-Tind ${ }^{d}$ antibody injected into the tail vein of recipient mice induces a cyclic pattern of either suppression or enhancement of the primary PFC response against SRBCs. The data points show the effect of injecting antibody $(\sim 5 \mathrm{ng})$ from tissue culture supernatants of clone 9IIIA2 into each of three C.AL-20 adult recipients at days $0,1,4,5$, or 10 and challenging those recipients with $10^{8} \mathrm{SRBCs}$ in PBS on day 0 . In contrast to results reported earlier for antibody to $\mathrm{Tsu}^{\mathrm{d}}$ (refs 2,3 ) where injection at day 4 of low doses of antibody was effective and other injections in this time spectrum showed no alteration in the response, injection of anti-Tind ${ }^{\mathrm{d}}$ seems to have a reproducible dual role in the response. Data points represent the geometric mean \pm s.e., $n=3$ mice. Three similar experiments yielded the same pattern with variations in the lag period before enhancement from 1 to 4 days. $a$ And $b$ represent two separate experiments and show the variation in kinetics of this regulation using the same reagents. These cyclic waves are strain specific for C.AL-20 but not for BALB/c.
Table 1 Strain-specific enhancement of the PFC response to SRBCs limits the gene coding for the Tind ${ }^{\mathrm{d}}$ molecule to the IgT region of chromosome 12

\begin{tabular}{|c|c|c|c|}
\hline \multirow[t]{2}{*}{$a$} & \multicolumn{3}{|c|}{ Strain } \\
\hline & C.AL-20 & $\mathrm{BALB} / \mathrm{c}$ & C.B.AL-1 \\
\hline (control) & $21,000 \div 1.02$ & $74,903 \times 1.79$ & $56,475 \times 1.34$ \\
\hline 0.1 & $35,327 \times 1.15$ & $88,545 \times 1.15$ & $58,000 \times 1.10$ \\
\hline 1.0 & $42,085 \times 1.03$ & ND & $58,240 \times 1.21$ \\
\hline 2.0 & $44,348 \times 1.17$ & $69,654 \times 1.10$ & $58,780 \times 1.22$ \\
\hline $5.0 P=<0.001$ & $53,665 \times 1.28 \div$ & $73,010 \times 1.05$ & $58,981 \times 1.10$ \\
\hline 50.0 & $25,258 \times 1.08$ & $89,000 \times 1.03$ & $55,300 \times 1.12$ \\
\hline 200.0 & $20,080 \times 1.03$ & ND & ND \\
\hline$b$ & \multicolumn{3}{|c|}{ Genotype of strains used } \\
\hline $\begin{array}{l}\text { C.AL-20 } \\
\text { BALB/c } \\
\text { C.B.AL-1 }\end{array}$ & \multicolumn{3}{|c|}{$\begin{array}{l}V h^{d} I g h-1^{d} T s u^{d+} P_{r e}{ }^{0} \\
V h^{a} I g h-1^{a} T s u^{d-} P r e^{0} \\
V h_{x}^{d} I g h-1^{b} T s u_{x}^{d-} P r e^{0}\end{array}$} \\
\hline
\end{tabular}

* Monoclonal antibody directed against Tind ${ }^{d}$ (clone 9IIIA2) was injected i.v. in recipient mice differing genetically in the IGh-1 linked genes (see $b$ ). A range of dilution of tissue culture supernatant containing antibody was injected on day 4 and the primary day-3 PFC response of mice challenged i.v. with $10^{8}$ SRBCs on day 0 was measured. Two of the C.AL-20 (Igh-1 $\left.{ }^{\text {d }}\right)$ mice were enhanced for the geometric mean response ( $5 \mathrm{ng}$ TCS) in comparison with control mice not treated with antibody $(0 \mathrm{ng})$. These data are from one of five experiments showing a similar pattern of stimulation. PFC values were obtained by the Cunningham plaque chamber assay ${ }^{26}$ as previously reported ${ }^{2,3}$.

$\uparrow$ The normalized grand geometric mean $\underset{\div}{\lessgtr}$ standard error of 15 mice in five separate experiments was $52,987 \stackrel{\times}{\div} 1.23$ for control value but 108,710 PFC $\stackrel{\times}{\div} 1.47$ for those treated with $5 \mathrm{ng}$ of antibody $(n=15, P=<0.001$ in double-tailed Student's $t$-test).

response, the antibody probably activates or stimulates a cell, possibly cross-linking that cell membrane through recognition of conserved structures on the receptor or 'constant regions'. Therefore, both $\mathrm{Tsu}^{\mathrm{d}}$ alloantiserum and Tind ${ }^{\mathrm{d}}$ monoclonal alloantibody appear to act as activators for regulatory cells for the immune response. The kinetics of activation by these two reagents are very different ${ }^{2,3}$. We cannot exclude the possibility that both antigens are on mutually overlapping cell populations, but the visual typing suggests they are on separate cells with related or tandem functions.

The molecular weights of Tsu ${ }^{d}$ and Tind ${ }^{d}$ are similar to those described for SRBC suppressor factor secreted from an Lyt-2, $3^{+}$cell line maintained with T-cell growth factor (MW 69,000) ${ }^{15}$ and the product of a hybrid $\mathrm{T}$-cell line secreting a molecule (MW 62,000) specific for the Ars hapten ${ }^{16}$.

These data imply that two similar, but serologically distinct, T-cell-specific antigens are encoded by closely linked genes on chromosome 12 . We have not proved that these antigens are $\mathrm{T}$-cell receptors for antigen nor has $\mathrm{Tind}^{\mathrm{d}}$ been mapped by recombination. It is possible that the markers $\mathrm{Tsu}^{\mathrm{d}}$ and Tind ${ }^{\mathrm{d}}$ are unique differentiation antigens involved in the expression of cell-surface antigens, facilitating expression of antigen-binding molecules. Lyt-2 differentiation antigens are co-expressed with antigen receptors on cytotoxic T cells ${ }^{17,18}$. However, we favour the hypothesis that these antigens represent constant regions on T-cell receptors for antigen ${ }^{19}$ with some analogy to the immunoglobulin heavy chains. The map positions of these genes suggest they may have arisen from the same primordial domain as the immunoglobulin heavy-chain genes and were evolutionarily modified to function in cellular recognition.

We thank Ms L. Riendeau for technical assistance. This research was supported by NIH grants AI 15262-03, CA17442-01 and CA-23776-04. G.M.S. is a fellow of the MRC of Canada.

Received 19 May; accepted 18 August 1981

1. Owen, F. L., Riblet, R. \& Taylor, B. A. J. exp. Med. 153, 801 (1981).

2. Owen, F. L., Finnegan, A., Gates, E. R. \& Gottlieb, P. D. Eur. J. Immun. 9, 948 (1979).

3. Owen, F. L. J. Immun. 124, 1411 (1980).

4. Owen, F. L. J. supramolec. Struct. 14, 175 (1980)

5. Owen, F. L., Riblet, R. \& Gottlieb, P. D. Eur. J. Immun. 11 (1981).

6. Owen, F. L., Ju, S.-T. \& Nisonoff, A. J. exp. Med. 145, 1559 (1977)

7. Kuettner, M. G., Wang, A. L. \& Nisonoff, A. J. exp. Med. 135, 579 (172).

8. Fanger, M. W., Hart, D. A., Wells, J. V. \& Nisonoff, A. J. Immun. 105, 1484 (1970)

9. Weinberger, J. Z., Benacerraf, B. \& Dorf, M. E. J. exp. Med. 151, 1413 (1980).

10. Riblet, R. in Organization of Antibody Genes (eds Sercarz, E. E. \& Herzenberg, L.) 83 (Liss, New York, 1977).

11. Jerne, N. K. Ann. Immun. 125C, 373 (1974). 
12. Kluskens, L. \& Köhler, H. Proc. natn. Acad. Sci. U.S.A. 71, 5083 (1974).

13. Kelsoe, G., Isaak, D. \& Cerny, J. J. exp. Med. 151, 289 (1980).

14. Eardley, D. D. et al. J. exp. Med. 148, 1106 (1978).

15. Fresno, M., Boudreau, L. M., Nabel, G. \& Cantor, H. J. exp. Med. 153, 1246 (1981)

16. Pacifico, A. \& Capra, J. D. J. exp. Med. 152, $1289(1980)$

17. Nakayama, E., Shiku, H., Stockert, E., Oettgen, H. F. \& Old, L. J. Proc. natn. Acad. Sci. U.S.A. 76, 1977 (1979).

18. Dialynas, D. P., Loken, M. R., Glasebrook, A. L. \& Fitch, F. W. J. exp. Med. 153, 595 (1981)

19. Owen, F. L. \& Spurll, G. M. in Idiotypes (eds Janeway, C. A., Sercarz, E., Wigzell, H. \& Fox, C.) 20 (Academic, New York, 1981)

20. Geckler, W., Blomberg, B., DePreval, C. \& Cohn, M. Cold Spring Harb. Symp. quant. Biol. 51, 748 (1976).

21. Leammli, A. K. Nature 227, 680 (1970).

22. Emmerson, S. G. \& Cone, R. E. J. Immun. 105, 1116 (1979).

23. Yelton, D. E., Diamond, B. A., Kwan, S. P. \& Scharff, M. D. Curr. Topics Microbiol. Immun. 81, 1 (1979).

24. Köhler, H. G. \& Milstein, C. Eur. J. Immun. 6, 511 (1975).

25. Spurll, G. M. \& Owen, F. L. J. immun. Meth. 135, $335(1980)$

26. Cunningham, A. J., Smith, J. B. \& Mercer, E. H. J. exp. Med. 124, 701 (1977).

Family studies define a new

histocompatibility locus, $S B$, between $H L A-D R$ and $G L O$

\section{Stephen Shaw*, Paula Kavathas $\dagger$, Marilyn S. Pollack $\ddagger$, Dominique Charmot§ \& Claude Mawas§}

*Immunology Branch, National Cancer Institute, National Institutes of Health, Bethesda, Maryland 20205, USA

†Department of Genetics, Stanford University, Stanford, California 94305, USA

$\ddagger$ Tissue Typing Laboratory, Sloan-Kettering Memorial Institute for Cancer Research, New York, New York 10021, USA

$\S$ Centre d'Immunologie INSERM-CRNS de Marseille-Luminy, Marseille, France

Gene products of the human $H L A$ region are the principal histocompatibility barrier to human allogeneic tissue transplantation'. In addition, $H L A$ genes regulate immune responses to environmental antigens ${ }^{2}$ and affect susceptibility to various diseases $^{3}$. Although the $H L A$ region has been studied intensively, only four histocompatibility loci $(H L A-A,-B,-C$ and $-D R$ ) have been identified within this 'supergene', but the existence of additional loci has been suggested by immunochemical $^{4-9}$ and genetic recombination ${ }^{10-15}$ studies. Recently, a new segregant series of five histocompatibility antigens, named 'secondary $B$ cell' (SB) antigens, was defined $^{16-18}$. We now report studies of 21 families which indicate that the gene encoding the SB antigens is closely linked to $H L A-D R$, but is distinguished from it by recombination in two families and can be mapped between $H L A-D R$ and $G L O$ in additional recombinant families.

The SB antigens are identified by a primed lymphocyte typing (PLT) system which has been optimized to ensure reproducible typing ${ }^{18}$. The 'reagents' used to define the five SB antigens are sets of cryopreserved primed lymphocytes from 10 different donor combinations, and include two reagents to define each of the five SB antigens. The same reagents have been used to SB type over 500 donors; the agreement between results for the two reagents defining each SB antigen is high $(r>0.86)$. A donor's cells are SB typed by using them to restimulate these 10 populations of primed cells; the assignment of SB specificities is then made by objective statistical analysis ${ }^{18}$ (although the appropriate scoring is generally apparent visually).

Population studies suggest that the five SB antigens are a simple mendelian segregant series of antigens in Hardy-Weinberg equilibrium ${ }^{18}$. The SB phenotype of donors was largely independent of their HLA-A, -B and -DR phenotypes ${ }^{18}$. Furthermore, family studies indicate that there is no statistically significant association between SB markers and the HLA-A, -B and -DR markers on 84 haplotypes. These data indicated that SB antigens might be products of a new locus, and this proposition has now been confirmed by two independent lines of inquiry: the family studies reported here and analysis of mutant cell lines ${ }^{19}$.
Table $1 S B / D R$ recombination in family Fa

\begin{tabular}{lccccccc}
\hline & \multicolumn{8}{c}{ Restimulating cells and their $H L A$} & haplotypes \\
& $\mathrm{A}$ & $\mathrm{B}$ & $\mathrm{J}$ & $\mathrm{F}$ & $\mathrm{G}$ & $\mathrm{I}$ & $\mathrm{D}$ \\
PLT reagents & $c d$ & $a b$ & $a c$ & $b c$ & $b d$ & $b / a d$ & $a d$ \\
SB1A & 86 & 26 & 80 & 57 & 7 & 23 & 51 \\
SB1B & 79 & 56 & 87 & 72 & 3 & 55 & 57 \\
& + & + & + & + & - & + & + \\
SB2A & 4 & 3 & 5 & 5 & 6 & 4 & 7 \\
SB2B & 14 & 3 & 7 & 9 & 10 & 7 & 7 \\
& - & - & - & - & - & - & - \\
SB3A & 3 & 8 & 4 & 6 & 2 & 7 & 4 \\
SB3B & 8 & 6 & 13 & 12 & 2 & 6 & 6 \\
& - & - & - & - & - & - & - \\
SB4A & 22 & 2 & 9 & 10 & 4 & 5 & 5 \\
SB4B & 10 & 3 & 9 & 6 & 4 & 6 & 5 \\
& - & - & - & - & - & - & - \\
SB5A & 22 & 16 & 22 & 26 & 5 & 11 & 12 \\
SB5B & 8 & 5 & 4 & 20 & 8 & 3 & 2 \\
& - & - & - & - & - & - & - \\
& 1 & & & & $b$ & & 1
\end{tabular}

SB assignment$$
1
$$

HLA haplotypes: $a, A w 24$ B14 DR3 Dw3 SB1 Glo*2; b, A11 B35 DRw6 Dw6 SBblank Glo*1; c, A23 B41 DRw5 Dw5 SB1 Glo*2; d, A30 Bw16 DRw6 Dw6 SBblank Glo*1; b/a, A11 B35 DRw6 Dw6SB1 Glo*2. The 10 SB-specific PLT reagents were restimulated with peripheral blood lymphocytes from donors as previously described ${ }^{16-18}$. Numeric data are given as \% relative response compared with a control positive stimulating cell; absolute c.p.m. for control responses $(100 \%$ reference) ranged between 10,006 and 99,773 . The determination of whether an antigen is present $(+)$ or absent $(-)$ was made by cluster analysis scoring of both reagents defining a specificity ${ }^{18}$. Family Fa has been typed using reagents of the 8th International Workshop and typed
twice for $\mathrm{GLO}^{10,11}$.

Studies of 21 families indicate that the SB antigens are encoded by a gene which is linked to $H L A$ (mostly closely to $H L A-D R$ ) but is separable by recombination from all known markers in this region. In the generation of the 77 offspring tested, there had been 80 meioses which could be evaluated for the segregation of $S B$, including 8 previously known to involve recombination in this region: 4 between $H L A$ and $G L O$ and 4 within the known $H L A$ region. In 70 of the other 72 informative meioses, $S B$ segregated with all $H L A$ and GLO markers; data on the remaining two are best explained by recombination between the known HLA genes and a new gene tightly linked to HLA.

Previous family studies ${ }^{16,17}$ have not separated the gene which encodes the SB antigens from HLA-DR; now we describe two families showing recombination between $S B$ and $D R$. The first family $(\mathrm{Fa})$ is well characterized and previously described by Mawas et al. ${ }^{10,11}$. The recombination in this family divided the ' $H L A-D$ region' into two subregions: a telomeric region $(D-\alpha)$ which included $H L A-D R$, and a centromeric region $(D-\beta)$ which included another gene(s) encoding antigens that induce allogeneic cellular proliferative responses. Members of this family were typed for SB antigens (Table 1) to determine whether the recombination would help to locate $S B$. The data from the parents and the non-recombinant siblings indicate that the $S B 1$ allele is present on both the $a$ and $c$ haplotypes, whereas the $b$ and $d$ haplotypes lack defined $S B$ alleles; this is inferred from the fact that all family members type as SB1 only, except for the $a c$ sibling $(G)$ who has no defined SB antigens. The data on the recombinant sibling I map SB1 centromeric to $H L A-D R$. The SB1 typing of the recombinant donor I resembles that of her $G L O$-identical ( $a d)$ sibling (D) much more than her serotypically identical $(b d)$ sibling $(G)$. Thus, sibling I inherited $S B 1$ together with $G L O * 2$ from the $a$ haplotype but inherited the $D R 6, B 35$ and $A 11$ alleles from the $b$ haplotype.

The second family (Kav) shows recombination between $D R$ and $S B$ (Table 2). The mother's cells (KAV1) were positive for both SB2 and SB3. However, the three children with the maternal $c$ haplotype $(A 1, B 8, D R 3)$ as well as the child 